\title{
A patient-centered approach to the burden of symptoms in patients with scleroderma treated with Bosentan: A prospective single-center observational study
}

\author{
ELENA REZUS $^{1 *}$, ALEXANDRA MARIA BURLUI $^{1 *}$, BOGDAN GAFTON $^{2}$, \\ TEODORA ALEXA STRATULAT ${ }^{2}$, GABRIELA RUSU ZOTA $^{3}$, ANCA CARDONEANU $^{1}$ and CIPRIAN REZUS ${ }^{4}$ \\ Departments of ${ }^{1}$ Rheumatology and Physiotherapy, ${ }^{2}$ Medical Oncology-Radiotherapy, ${ }^{3}$ Pharmacology, Clinical Pharmacology \\ and Algesiology, and ${ }^{4}$ Internal Medicine, 'Grigore T. Popa' University of Medicine and Pharmacy, 700115 Iasi, Romania
}

Received May 24, 2019; Accepted November 12, 2019

DOI: $10.3892 / \mathrm{etm} .2019 .8361$

\begin{abstract}
Systemic sclerosis (SSc) is a rare and complex autoimmune disease associated with poor vital and functional outcomes. The functional hindrance in patients derives from various disease-specific manifestations, including Raynaud's phenomenon and digital ulcers (DUs). Bosentan is an endothelin receptor antagonist capable of preventing the appearance of new DUs in patients with scleroderma. The present study aimed to evaluate the effects of Bosentan on the severity of Raynaud's phenomenon, DU-related symptoms and functional impairment during the first year of treatment. A prospective study that included adult patients with SSc admitted to the Rheumatology Department between January 2016 and January 2017 that were candidates for Bosentan therapy, was performed. All patients were asked to evaluate the burden of symptoms secondary to Raynaud's and DUs using a visual analogue scale (VAS), whereas functional hindrance was assessed via Health Assessment Questionnaire Disability Index (HAQ-DI). The outcomes were assessed at baseline and every 3 months during 1 year of therapy. Among the 41 patients included initially, 2 participants discontinued the treatment after 1 month due to adverse events (elevation of liver enzymes). The study cohort exhibited a significant improvement in HAQ-DI, VAS-R and VAS-DU scores in response to Bosentan therapy over the 1-year follow-up period. Higher scores at baseline predicted a weaker treatment-related improvement, with the risk of a poor outcome being increased
\end{abstract}

Correspondence to: Dr Gabriela Rusu Zota, Department of Pharmacology, Clinical Pharmacology and Algesiology, 'Grigore T. Popa' University of Medicine and Pharmacy, 16 Universitatii St, 700115 Iasi, Romania

E-mail: rusu.i.gabriela@umfiasi.ro

*Contributed equally

Key words: systemic sclerosis, bosentan, dyspnea, Raynaud's symptoms, microvascular changes by $220 \%$ for VAS-R, $116 \%$ for VAS-DU, whereas no increase was observed for HAQ-DI. The post-treatment improvement in VAS-DU levels was associated with a better outcome for HAQ-DI $(\mathrm{R}=0.44 ; \mathrm{P}=0.005)$. This association was not identified for VAS-R ( $\mathrm{R}=0.24 ; \mathrm{P}=0.137)$. Throughout the follow-up period, patients with dyspnea presented with significantly higher HAQ-DI scores compared with non-dyspneic patients. Bosentan therapy may indirectly influence functionality and quality of life in patients with scleroderma by reducing the burden of Raynaud's and DU-related symptoms. Nonetheless, patients with SSc with a decreased symptom burden at baseline exhibited improved outcomes.

\section{Introduction}

Systemic sclerosis $(\mathrm{SSc})$ is a rare autoimmune disease associated with a high risk of morbidity and mortality. The intricate pathogenic mechanisms involved in SSc comprise a substantial immune disturbance, microvascular and neural changes, together with an excessive deposition of collagen in the tissues subsequently leading to organ fibrosis $(1,2)$.

The burden of symptoms in scleroderma has been shown to derive from various manifestations including skin involvement, cardiopulmonary and peripheral vascular changes, renal, gastrointestinal, and musculoskeletal impairment $(3,4)$. Consequently, patients with SSc exhibit a considerably poorer quality of life compared to individuals suffering from other chronic skin conditions such as ichtyosis, atopic dermatitis, non-melanoma skin cancer, and vitiligo $(5,6)$. Furthermore, studies proved that considerable loss in work ability occurs as early as 3 years from the onset of SSc (7). Interestingly, the patient-centered approach to the burden of symptoms often provides different insights compared to the physicians' view on the severity of the disease $(8,9)$.

Vascular injury is virtually ubiquitous in scleroderma, making the assessment of microvascular damage imperative in these patients. Moreover, Raynaud's phenomenon marks the onset of the disease in the majority of cases and contributes to the appearance of functional hindrance and a decreased quality of life (10). While the initial trigger of vascular damage in SSc remains a matter of debate, recent 
evidence indicates that autoantibody profiles, abnormal cytotoxic $\mathrm{T}$ cell activity and reperfusion injury all participate in the development of SSc-related vasculopathy (11-13). It has also been stated that oxidative stress may play a role in the pathomechanisms of scleroderma, similar to other pathologies $(1,14,15)$.

Endothelin-1 (ET-1) is produced by a wide variety of cells such as macrophages, fibroblasts, neutrophils, cardiac muscle and vascular endothelial cells $(16,17)$. Given its potent vasoconstrictor activity together with its pro-inflammatory and pro-fibrotic effects, ET-1 has been proven to play a central role in the pathogenesis of SSc. Endothelial cells, fibroblasts, vascular smooth muscle cells and neutrophils express endothelin-specific receptors (ET $\alpha$ and $\beta$ ) (16). Furthermore, ET-1 acts as a mediator of the transforming growth factor- $\beta$ (TGF- $\beta$ ) signaling pathway, thus promoting the appearance and development of fibrotic changes in SSc (18).

The impact of digital ulcers (DUs) on disability and health-related quality of life in SSc has long been demonstrated. Bosentan is an endothelin receptor antagonist capable of preventing the onset of new DUs in scleroderma patients with an added effect on fibro-proliferative vascular remodeling and pulmonary arterial hypertension (PAH) (19-21). Recent research indicates that along with other therapies targeting the same factor, bosentan treatment is accompanied by an improvement in patients' quality of life and/or functional capacity (22-24).

Our primary aim was to establish whether or not scleroderma patients experience an improvement in functionality during the first year of treatment with bosentan. Secondary objectives involved the analysis of the burden of disease with regard to Raynaud's phenomenon and DUs, as well as the identification of factors that could influence patient-perceived outcomes in our study group.

\section{Materials and methods}

We conducted a prospective observational study in which we included adult individuals with SSc that underwent Bosentan therapy between January 2016 and January 2017. The inclusion criteria were the following: confirmed SSc diagnosis (2013 European League Against Rheumatism criteria), elligible and willing to begin Bosentan therapy, informed consent given by subjects in written form before the initiation of study screening, age over 18 years, and Body Mass Index (BMI) between 18.5 and $30 \mathrm{~kg} / \mathrm{m}^{2}$. The exclusion criteria were: age $<18$ years, patients' refusal to participate, overlap syndromes (25), scleroderma sine scleroderma (26), current treatment with Cyclosporine A (27), Cyclophosphamide (28), phosphodiesterase type 5 inhibitors $(29,30)$ or prostacyclin analogs $(31,32)$, and severe or uncontrolled cardiac, liver or renal involvement (33).

The onset of the disease was defined as the initial appearance of Raynaud's phenomenon. Patients were stratified with respect to disease phenotype as diffuse cutaneous $\mathrm{SSc}(\mathrm{dcSSc})$ or limited cutaneous SSc (lcSSc) in accordance with the LeRoy classification.

We determined capillaroscopic patterns utilizing a FedMed Digitale 100N digital microscope at a magnification rate of 200X.
The study participants were asked to evaluate the burden of Raynaud's symptoms as well as DUs with the help of a visual analogue scale (VAS) which ranged from 0 millimeters (best/no symptoms) to $100 \mathrm{~mm}$ (worst/most intense symptoms). We assessed disease-related functional impairment using the Health Assessment Questionnaire Disability Index (HAQ-DI). The patient-perceived burden of symptoms and the HAQ-DI were documented at baseline, at 3, 6, 9 months, and at 12 months post-treatment with bosentan.

The statistical analysis of the data was performed using Microsoft Office Excel and IBM SPSS Statistics v20 for Windows. We applied the student t-test to compare the characteristics of different subgroups of patients and the paired t-test to determine the differences between evaluations (34). We used odds ratio (OR) to assess the impact of clinical characteristics on functional impairment and patient-reported outcomes in our study group. In the contingency tables, we applied the chi $^{2}$ test and Fisher's exact test (where chi $^{2}$ did not demonstrate statistical consistency). In order to highlight the relationships between different variables, we used either Pearson's or Spearman's correlation coefficients depending on the distribution of variables. The statistical significance was a priori set at $<0.05$.

The study protocol was approved by the Ethics Committee on Research of the Clinical Rehabilitation Hospital (Iasi, Romania).

\section{Results}

Of the 41 patients recruited, 28 were classified as dcSSc $(68.3 \%)$ and 13 as $1 c S S c$ (31.7\%). The time from diagnosis to study enrollment ranged between 6 months and 33 years. Although none of the patients were smokers, the majority of participants $(23,56.1 \%)$ reported having dyspnea and regarded it as a major burden on their general health. Dyspnea was not significantly more frequent in elderly patients compared to the rest of the group (Fisher's exact test, $\mathrm{P}=0.447$ ).

The patients were treated with $62.5 \mathrm{mg}$ twice daily for 4 weeks, then $125 \mathrm{mg}$ twice daily with frequent monitoring of liver function (prior to inclusion, after the first 4 weeks, at 6 weeks, and then monthly until the end of the study), complete blood work (monthly). All subjects were started on a personalized rehabilitation program prior to the study and continued it over the entire follow-up period.

The patient-reported severity of Raynaud's symptoms (VAS-R) and DU-related discomfort (VAS-DU) received between 50 and 100 points on the VAS at the beginning of the study. Score values did not differ across the dcSSc and lcSSc groups, with only a trend towards significance for HAQ-DI $(\mathrm{P}=0.051)$. The baseline characteristics of the study population are summarized in Table I.

Most of the patients (95.12\%) exhibited capillaroscopic changes suggestive of either the active $(\mathrm{n}=20,48.8 \%)$ or the late $(\mathrm{n}=19,46.3 \%) \mathrm{SSc}$ patterns. The severity of microvascular changes was positively correlated with the duration of symptoms ( $\mathrm{R}=0.39, \mathrm{P}=0.014)$, and the burden of the disease as reflected by Raynaud's syndrome $(\mathrm{R}=0.46, \mathrm{P}=0.003)$, $\mathrm{DUs}$ $(\mathrm{R}=0.038, \mathrm{P}=0.017)$, HAQ-DI $(\mathrm{R}=0.55, \mathrm{P}<0.001)$.

Increased disability index values were accompanied by higher VAS levels for Raynaud's ( $\mathrm{R}=0.55, \mathrm{P}<0.001)$, and DUs 
Table I. Baseline characteristics of the study population.

\begin{tabular}{|c|c|}
\hline Characteristics & Mean $( \pm \mathrm{SD}) /$ no $(\%)$ \\
\hline Age, years & $58.17( \pm 12.1)$ \\
\hline $30-39$ & $3(7.3)$ \\
\hline $40-49$ & $9(22)$ \\
\hline $50-59$ & $7(17.1)$ \\
\hline $60-69$ & $15(36.6)$ \\
\hline $70-79$ & $6(14.6)$ \\
\hline 80 & $1(2.4)$ \\
\hline Disease duration, years & $9.66( \pm 6.8)$ \\
\hline \multicolumn{2}{|l|}{ Sex } \\
\hline Female & $31(75.6)$ \\
\hline Male & $10(24.4)$ \\
\hline Female:Male ratio & $3: 1$ \\
\hline \multicolumn{2}{|l|}{ Disease phenotype } \\
\hline dcSSc & $28(68.3)$ \\
\hline lcSSc & $13(31.7)$ \\
\hline \multicolumn{2}{|l|}{ Capillaroscopic pattern } \\
\hline Early & $2(4.9)$ \\
\hline Active & $20(48.8)$ \\
\hline Late & $19(46.3)$ \\
\hline \multicolumn{2}{|l|}{ Dyspnea } \\
\hline Present & $23(56.1)$ \\
\hline Absent & $18(43.9)$ \\
\hline \multicolumn{2}{|l|}{ Treatment } \\
\hline Low-dose oral steroids & $6(14.6)$ \\
\hline Calcium channel blockers & $27(65.9)$ \\
\hline \multicolumn{2}{|l|}{ Synthetic DMARDs } \\
\hline Methotrexate & $14(34.1)$ \\
\hline Azathioprine & $2(4.9)$ \\
\hline Hydroxychloroquine & $8(19.5)$ \\
\hline Mycophenolate mofetil & $1(2.4)$ \\
\hline VAS-R & $79.15( \pm 16.2)$ \\
\hline VAS-DU & $76.83( \pm 16.04)$ \\
\hline HAQ-DI & $1.65( \pm 0.68)$ \\
\hline
\end{tabular}

HAQ-DI, Health Assessment Questionnaire Disability; dcSSc, diffuse cutaneous systemic sclerosis; lcSSc, limited cutaneous systemic sclerosis; VAS-R, visual analogue scale-Raynaud's; VAS-DU, visual analogue scale-digital ulcers; DMARD, disease modifying anti-rheumatic drug.

$(\mathrm{R}=0.49, \mathrm{P}=0.002)$. Patients' age was also correlated with HAQ-DI $(\mathrm{R}=0.78, \mathrm{P}<0.001)$.

At baseline, the student t-test demonstrated statistically significant differences between the early/active and the late capillaroscopic patterns regarding VAS-R $(\mathrm{P}<0.001)$, VAS-DU $(\mathrm{P}=0.005)$, and HAQ-DI $(\mathrm{P}=0.001)$.

The dcSSc group displayed elevated odds ratio for dyspnea (OR=7.13, 95\% CI: 3.51-33.43), more severe microvascular changes $(\mathrm{OR}=8.4,95 \% \mathrm{CI}: 2.54-46.18)$ and an above-mean burden of Raynaud's symptoms (OR=3.4, 95\% CI: 1.81-14.24).
Patients over 60 years of age presented with higher odds of displaying elevated VAS-DU scores at baseline compared to the group mean $(\mathrm{OR}=2.06,95 \% \mathrm{CI}$ : 1.57-7.47). Female patients were more likely to report greater HAQ-DI $(\mathrm{OR}=2.85,95 \% \mathrm{CI}$ : 1.65-12.05).

Due to adverse effects manifested through an important increase in liver enzymes, two participants (both female, 65 and 68 years old without underlying liver disease) were unable to continue Bosentan therapy and dropped out from the study after one month. The two excluded patients demonstrated a rapid normalization of liver function tests after the discontinuation of Bosentan.

The remaining 39 patients were able to continue the treatment until the end of the study and exhibited a significant improvement in HAQ-DI, VAS-R, and VAS-DU scores over the one-year follow-up period $(\mathrm{P}<0.001$ for all parameters) (Table II).

The disability index scores did not differ substantially with regard to disease phenotype over the 12 months of treatment (HAQ-DI at 3 months: $\mathrm{P}=0,428$; HAQ-DI at 6 months: $\mathrm{P}=0.142$; HAQ-DI at 9 months: $\mathrm{P}=0.503$; HAQ at 12 months: $\mathrm{P}=0.152$ ). However, when analyzed separately, both dcSSc and lcSSc patients exhibited significant improvements in all the scores tested $(\mathrm{P}<0.001)$. The mean HAQ-DI levels with respect to disease phenotype are shown in Fig. 1.

The post-treatment amelioration of VAS-R, VAS-DU and HAQ-DI was not found to be significantly different across the capillaroscopic pattern subgroups at 12 months $(\mathrm{P}>0.05$; Fig. 2).

The values of VAS-DU, VAS-R, and HAQ-DI as well as response rates were similar in female and male participants. The post-treatment improvement in VAS-DU levels was associated with better outcomes in HAQ-DI $(\mathrm{R}=0.44, \mathrm{P}=0.005)$. This relationship was not proven for VAS-R $(\mathrm{R}=0.24$, $\mathrm{P}=0.137)$.

Throughout the follow-up period, patients with dyspnea presented with significantly higher HAQ-DI levels (Fig. 3) $(\mathrm{P}<0.001$ at baseline, at 3 months, and 12 months; $\mathrm{P}=0.004$ at 6 months, and $\mathrm{P}=0.015$ at 9 months, respectively).

Moreover, dyspneic participants were prone to experiencing inferior results with respect to HAQ-DI amelioration $(\mathrm{P}=0.005)$ (Fig. 4). The risk of exhibiting a below-mean improvement was increased by $41 \%$ in these patients.

Higher scores at baseline (above the mean value for the entire group) predicted weaker results after one year of treatment, the risk being increased by $220 \%$ for VAS-R, $116 \%$ for VAS-DU, but not HAQ-DI. Patients with elevated disability index score values at baseline experienced more dramatic improvements post-treatment $(\mathrm{R}=0.48, \mathrm{P}=0.002)$.

The late capillaroscopic pattern was associated with a weaker amelioration of the scores tested, with a $109 \%$ risk elevation for VAS-DU, $43 \%$ for VAS-R, and 24\% for HAQ-DI. Patients with a disease duration of over 5 years displayed an increased risk for poor outcome by $104 \%$ for VAS-R and $64 \%$ for HAQ-DI.

The risk of experiencing a below-mean improvement in functionality index scores was increased by $64 \%$ in patients over 60 years of age. However, this category was more likely to exhibit better outcomes by $30 \%$ in terms of Raynaud's symptoms and by $18 \%$ in VAS-DU scores. 
Table II. Analysis of the scores during the 12-month follow-up period.

\begin{tabular}{lccccc}
\hline Score & $\begin{array}{c}\text { First visit } \\
(3 \text { months })\end{array}$ & $\begin{array}{c}\text { Second visit } \\
(6 \text { months })\end{array}$ & $\begin{array}{c}\text { Third visit } \\
(9 \text { months })\end{array}$ & $\begin{array}{c}\text { Fourth visit } \\
(12 \text { months })\end{array}$ \\
\hline VAS-R & $14.27(9.38-19.15)$ & $24.61(20.39-28.84)$ & $31.03(25.67-36.38)$ & $38.71(33.26-44.17)$ \\
VAS-DU & $21.34(14.44-28.24)$ & $31.92(26.69-37.15)$ & $41.28(34.23-48.33)$ & $51.41(44.45-58.37)$ & $<0.001$ \\
HAQ-DI & $0.47(0.36-0.58)$ & $0.48(0.32-0.64)$ & $0.71(0.54-0.88)$ & $0.72(0.57-0.87)$ & $<0.001$ \\
\hline
\end{tabular}

Mean differences were compared with baseline levels (95\% CI shown in parentheses). P-values shown were calculated for baseline vs. 12 months. HAQ-DI, Health Assessment Questionnaire Disability; VAS-R, visual analogue scale-Raynaud's; VAS-DU, visual analogue scale-digital ulcers.

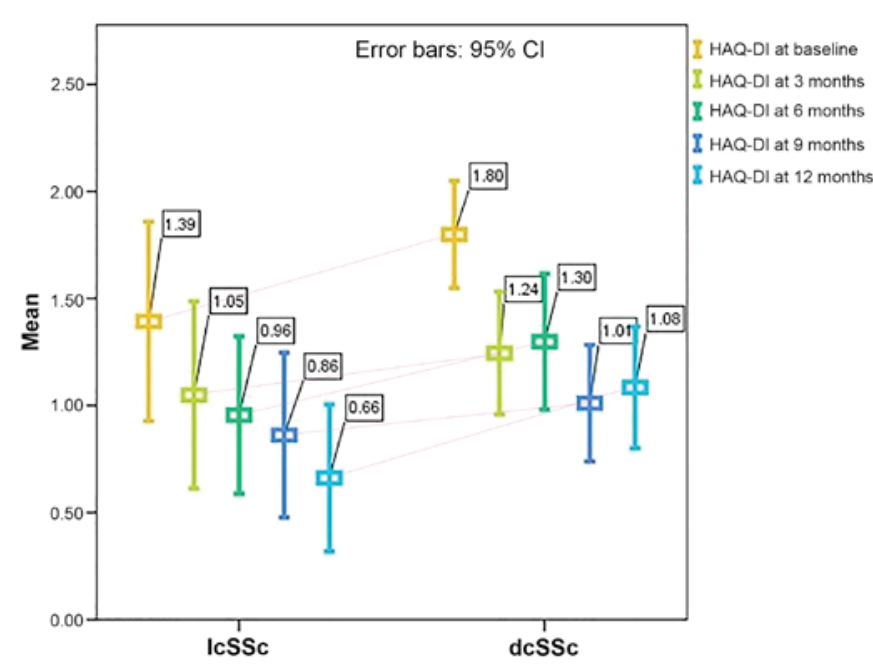

Figure 1. HAQ-DI scores during the follow-up period with respect to disease phenotype. HAQ-DI, Health Assessment Questionnaire Disability Index; dcSSc, diffuse cutaneous systemic sclerosis; lcSSc, limited cutaneous systemic sclerosis.

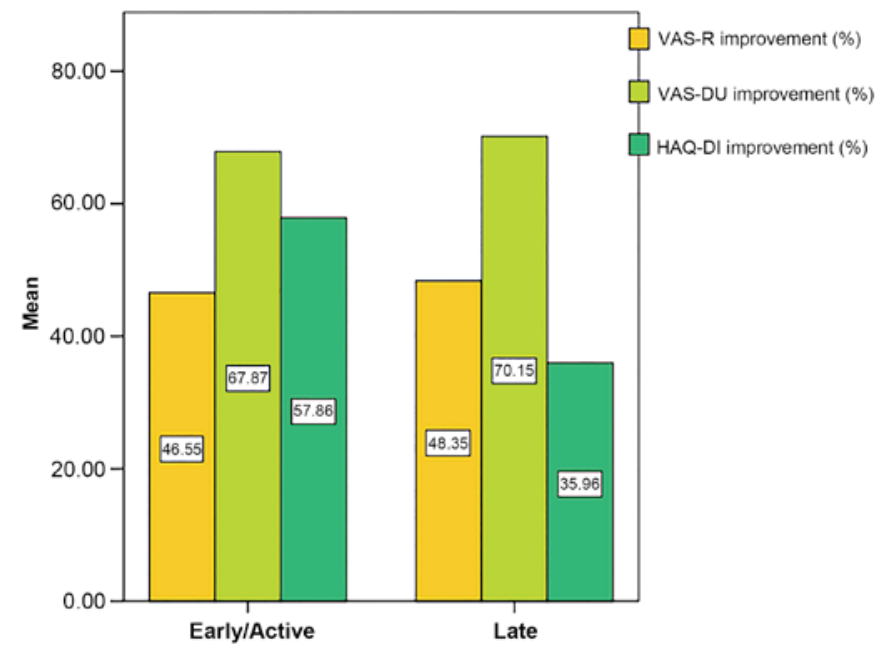

Figure 2. Score improvement (\% of baseline value) after 12 months of treatment according to capillaroscopic pattern subgroups. HAQ-DI, Health Assessment Questionnaire Disability Index; VAS-R, visual analogue scale-Raynaud's; VAS-DU, visual analogue scale-digital ulcers.

At 12 months, 26 patients were under treatment with calcium channel blockers $(66.7 \%)$. Nevertheless, concomi-

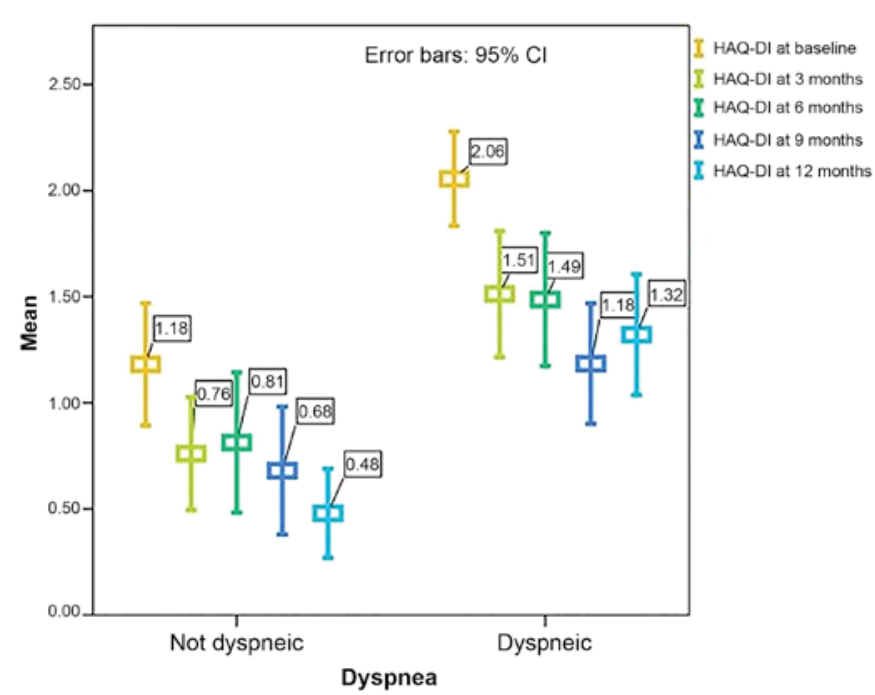

Figure 3. HAQ-DI values throughout the follow-up period in patients with and without dyspnea. HAQ-DI, Health Assessment Questionnaire Disability Index.

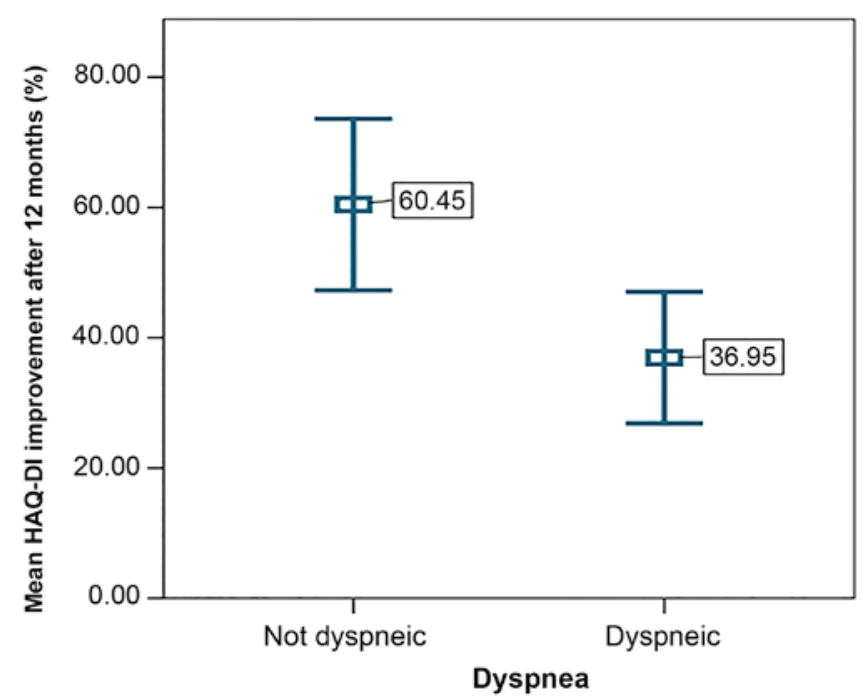

Figure 4. Mean HAQ-DI improvement at 12 months vs. baseline values (\%) in patients with and without dyspnea. HAQ-DI, Health Assessment Questionnaire Disability Index.

tant treatment with calcium channel blockers did not result in a significantly greater amelioration of VAS-R $(P=0.971)$, 


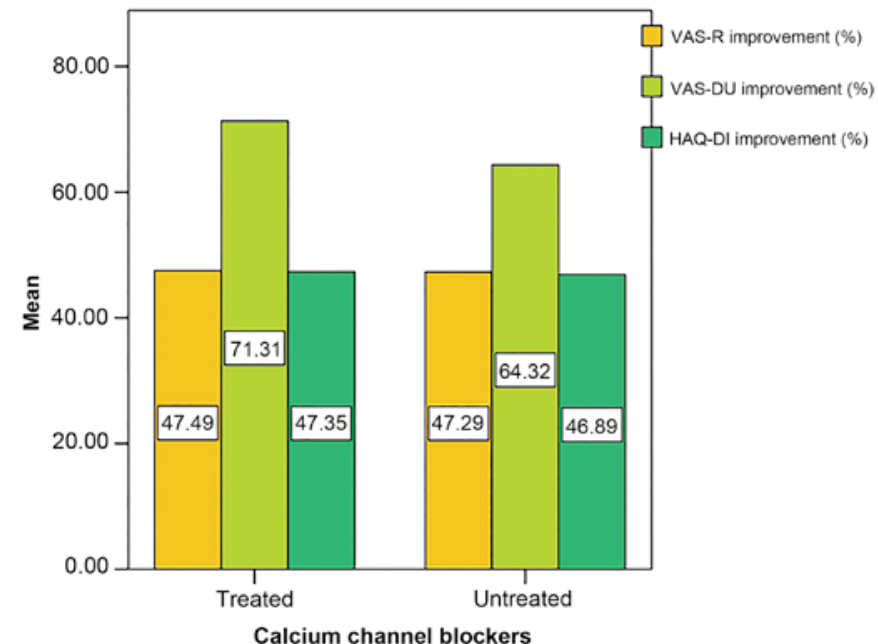

Figure 5. Score improvement ( $\%$ of baseline value) at 12 months in patients with or without concomitant treatment with calcium channel blockers HAQ-DI, Health Assessment Questionnaire Disability Index; VAS-R, visual analogue scale-Raynaud's; VAS-DU, visual analogue scale-digital ulcers.

VAS-DU ( $\mathrm{P}=0.479)$ or HAQ-DI $(\mathrm{P}=0.960)$ compared to the rest of the group (Fig. 5).

The use of synthetic DMARDs did not exhibit a notable influence on functional outcomes, VAS-R or VAS-DU at 12 months of Bosentan therapy $(\mathrm{P}=0.148, \mathrm{P}=0.128, \mathrm{P}=0.691)$. Moreover, we found no association between concomitant treatment with low-dose glucocorticoids and the amelioration of VAS-R, VAS-DU or HAQ-DI scores in our study population $(\mathrm{P}=0.384, \mathrm{P}=0.816, \mathrm{P}=0.508)$.

\section{Discussion}

SSc is a chronic disease accompanied by an elevated risk of disability and a high mortality rate despite currently available treatment $(35,36)$. It has been shown that multiple factors contribute to the potentially severe disease-related manifestations and the hindrance of patients' functional capacity $(37,38)$. Together with an extended fibrosis of the skin, joint contractures, sarcopenia, gastrointestinal and cardiopulmonary involvement, the presence of Raynaud's phenomenon and DUs have an important impact on daily life activities and work-related endeavors $(8,38)$.

Ischemic DUs are a common and serious health issue in scleroderma, often leading to considerable hand disability and pain in these patients $(35,39)$, which is especially relevant since chronic pain constitutes a leading cause of life quality decrease frequently requiring therapeutic management (40-42). In our study population, the burden of Raynaud's phenomenon and DU-related symptoms as assessed by patients (subjective) were correlated with the capillaroscopic anomalies at baseline (objective). The severity of microvascular findings also influenced the patient-perceived outcome in terms of DU-related discomfort post-treatment. These results support the association between objectively measured severity of microvascular damage and the patients' view on the burden of symptoms. Admitting that physicians habitually place their focus on the objective assessment of disease-related impairment, findings are frequently disparate from the patients' perspective $(39,43,44)$.

Our research concentrated mainly on patient-reported outcomes during the first year of endothelin-1 receptor antagonist therapy. The majority of patients who required treatment with bosentan for active DUs presented with the diffuse phenotype. The latter were more likely to have dyspnea, greater HAQ-DI scores at baseline $(\mathrm{P}=0.051)$ and more severe capillaroscopic changes. Recent studies have reported more severe organ manifestations, higher mortality rates in patients with dcSSc compared to lcSSc $(45,46)$. However, the post-treatment disability index scores were not substantially different with respect to disease phenotype in our cohort.

The patient-centered approach to disability in scleroderma leads to the conclusion that SSc-related dyspnea often constitutes one of the main factors involved in the decrement of life quality as well as disability (47-49). According to recent data from the DeSScipher project within the EUSTAR (European Scleroderma Trials and Research) group, dyspnea and the presence of DUs emerge as major determinants of functional impairment in SSc patients (8). Other studies have reported similar findings regarding the importance of dyspnea in SSc-related quality of life $(50,51)$. Our results highlight the role of dyspnea in the persistent functional hindrance amongst the study group, dyspneic patients presenting with significantly higher HAQ-DI scores at every visit despite all subjects following a personalized rehabilitation program $(52,53)$. Furthermore, dyspneic patients in our cohort were more likely to report poorer improvement in HAQ-DI after one year of bosentan therapy compared to the non-dyspneic subgroup.

Current therapeutic options for SSc are limited and thought of as insufficient $(54,55)$, patients often using over-the-counter drugs for symptom management (56). It has been demonstrated that calcium channel blockers exert a positive effect on vascular changes in scleroderma $(57,58)$. However, the association of Bosentan with calcium channel blockers did not result in better outcomes in our study population.

Although research shows that immunosuppressive agents have beneficial effects on SSc patients' outcomes (59-63), concomitant treatment with synthetic DMARDs did not influence the results after one year of Bosentan treatment. The same was true for low-dose oral glucocorticoids in our cohort $(64,65)$.

Bosentan has been proven to diminish the appearance of new DUs in SSc patients (66). For the entire study cohort, HAQ-DI scores were significantly improved after one year of treatment with Bosentan. Hereof, our results were similar to those obtained by Mouthon et al (22) which indicated a lower level of disability and improved hand function at 12 months.

During the follow-up period, Bosentan therapy was proven beneficial in our study population irrespective of disease phenotype, HAQ-DI improvement correlating with that of VAS-DU but not VAS-R, thus suggesting the important role of DU-related symptoms in scleroderma patients' functional impairment (22). However, the currently available literature reports discrepant results in this respect. Matucci-Cerinic et al (66) did not obtain functional improvement in patients treated with Bosentan versus placebo at 24 
weeks. In contrast to these results, Nguyen et al (67) reported a significant amelioration of functional scores but not Raynaud's phenomenon in their study cohort. Nevertheless, more research is needed in order to analyze long-term effects.

$\mathrm{SSc}$ is associated with a considerable decrease in functionality and quality of life. Nonetheless, the patient-perceived burden of the disease is seldom superposed to physicians' view on the severity of organ impairment. Along with the limited therapeutic options, the potentially severe multisystem involvement that accompanies this diagnosis leads to a negative prognosis for SSc patients, especially if they exhibit a pronounced burden of symptoms at the moment of diagnosis. The present observational study faces certain limitations such as the absence of a control group, the small number of patients included and the short follow-up period. However, Bosentan treatment led to a significant decrease in VAS-R, VAS-DU as well as HAQ-DI scores irrespective of disease phenotype suggesting a positive effect on the patient-perceived severity of vascular involvement and functional hindrance. Future research addressing patient-reported outcomes may provide further insight on the effect of long-term endothelin-1 receptor antagonist therapy in scleroderma.

\section{Acknowledgements}

Not applicable.

\section{Funding}

No funding was received.

\section{Availability of data and materials}

All data generated or analyzed during this study are included in this published article.

\section{Authors' contributions}

ER, AMB, GRZ and AC conceived and designed this article, performed the experiments and analysis, and wrote the manuscript. BG, TAS and CR interpreted the data, drafted the manuscript and made critical revisions. All authors researched the literature, discussed the results and reviewed and approved the final manuscript.

\section{Ethics approval and consent to participate}

The study protocol was approved by the Ethics Committee on Research of the Clinical Rehabilitation Hospital (Iasi, Romania). All patients were required to provide informed consent beforehand.

\section{Patient consent for publication}

Not applicable.

\section{Competing interests}

The authors declare that they have no competing interests.

\section{References}

1. Pattanaik D, Brown M, Postlethwaite BC and Postlethwaite AE: Pathogenesis of systemic sclerosis. Front Immunol 6: 272, 2015.

2. Choi MY and Fritzler MJ: Progress in understanding the diagnostic and pathogenic role of autoantibodies associated with systemic sclerosis. Curr Opin Rheumatol 28: 586-594, 2016.

3. Crincoli V, Fatone L, Fanelli M, Rotolo RP, Chialà A, Favia G and Lapadula G: Orofacial manifestations and temporomandibular disorders of systemic scleroderma: An observational study. Int J Mol Sci 17: 1189, 2016.

4. Paik JJ, Wigley FM, Mejia AF and Hummers LK: Independent association of severity of muscle weakness with disability as measured by the health assessment questionnaire disability index in scleroderma. Arthritis Care Res (Hoboken) 68: 1695-1703, 2016.

5. Bretterklieber A, Painsi C, Avian A, Wutte N and Aberer E: Impaired quality of life in patients with systemic sclerosis compared to the general population and chronic dermatoses. BMC Res Notes 7: 594, 2014.

6. Nguyen C, Ranque B, Baubet T, Bérezné A, Mestre-Stanislas C, Rannou F,Papelard A,Morell-Dubois S, Revel M, Moro MR, et al; Groupe Français de Recherche sur la Sclérodermie: Clinical, functional and health-related quality of life correlates of clinically significant symptoms of anxiety and depression in patients with systemic sclerosis: A cross-sectional survey. PLoS One 9: e90484, 2014.

7. Sandqvist G, Hesselstrand R, Petersson IF and Kristensen LE: Work disability in early systemic sclerosis: A longitudinal population-based cohort study. J Rheumatol 42: 1794-1800, 2015.

8. Jaeger VK, Distler O, Maurer B, Czirják L, Lóránd V, Valentini G, Vettori S, Del Galdo F, Abignano G, Denton C, et al: Functional disability and its predictors in systemic sclerosis: A study from the DeSScipher project within the EUSTAR group. Rheumatology (Oxford) 57: 441-450, 2018.

9. Ziemek J, Man A, Hinchcliff M, Varga J, Simms RW and Lafyatis R: The relationship between skin symptoms and the scleroderma modification of the health assessment questionnaire, the modified Rodnan skin score, and skin pathology in patients with systemic sclerosis. Rheumatology (Oxford) 55: 911-917, 2016.

10. Morrisroe K, Stevens W, Huq M, Prior D, Sahhar J, Ngian GS, Celermajer D, Zochling J, Proudman S and Nikpour M; Australian Scleroderma Interest Group (ASIG): Survival and quality of life in incident systemic sclerosis-related pulmonary arterial hypertension. Arthritis Res Ther 19: 122, 2017.

11. Denton CP: Systemic sclerosis: From pathogenesis to targeted therapy. Clin Exp Rheumatol 33 (Suppl 92): S3-S7, 2015.

12. Denton CP: Advances in pathogenesis and treatment of systemic sclerosis. Clin Med (Lond) 16: 55-60, 2016.

13. Burlui A, Cardoneanu A, Macovei LA, Arhire L, Graur M and Rezus E: Is there a place for anti-nucleosome antibody assessment in scleroderma? Rom J Rheumatol 27: 169-173, 2018.

14. Ilie AC, Alexa ID, Moroșanu AI, Covic A and Cepoi V: Effects of oxidative stress and pharmacologycal treatment on geriatric syndromes in the hospitalised elderly patients. Farmacia 64: 588-593, 2016.

15. Rezus E, Cardoneanu A, Burlui A, Luca A, Codreanu C, Tamba BI, Stanciu GD, Dima N, Bădescu C and Rezuș C: The Link Between Inflammaging and Degenerative Joint Diseases. Int J Mol Sci 20: 614, 2019.

16. Shiwen X, Leask A, Abraham DJ and Fonseca C: Endothelin receptor selectivity: Evidence from in vitro and pre-clinical models of scleroderma. Eur J Clin Invest 39 (Suppl 2): 19-26, 2009.

17. Ortega Mateo A and de Artiñano AA: Highlights on endothelins: A review. Pharmacol Res 36: 339-351, 1997.

18. Shi-Wen X, Rodríguez-Pascual F, Lamas S, Holmes A Howat S, Pearson JD, Dashwood MR, du Bois RM, Denton CP, Black CM, et al: Constitutive ALK5-independent c-Jun $\mathrm{N}$-terminal kinase activation contributes to endothelin-1 overexpression in pulmonary fibrosis: Evidence of an autocrine endothelin loop operating through the endothelin A and B receptors. Mol Cell Biol 26: 5518-5527, 2006.

19. Mouthon L, Mestre-Stanislas C, Bérezné A, Rannou F, Guilpain P, Revel M, Pagnoux C, Guillevin L, Fermanian J and Poiraudeau S: Impact of digital ulcers on disability and health-related quality of life in systemic sclerosis. Ann Rheum Dis 69: $214-217,2010$ 
20. Li W and Frech TM: The critical need for accurately defining digital ulcers in scleroderma. J Scleroderma Relat Disord 2: 69-71, 2017.

21. Schieir O, Thombs BD, Hudson M, Boivin JF, Steele R, Bernatsky S, Hanley J and Baron M; Canadian Scleroderma Research Group: Prevalence, severity, and clinical correlates of pain in patients with systemic sclerosis. Arthritis Care Res (Hoboken) 62: 409-417, 2010.

22. Mouthon L, Carpentier PH, Lok C, Clerson P, Gressin V, Hachulla E, Bérezné A, Diot E, Van Kien AK, Jego P, et al; ECLIPSE study investigators: Controlling the digital ulcerative disease in systemic sclerosis is associated with improved hand function. Semin Arthritis Rheum 46: 759-766, 2017.

23. Bose N, Bena $\mathbf{J}$ and Chatterjee S: Evaluation of the effect of ambrisentan on digital microvascular flow in patients with systemic sclerosis using laser Doppler perfusion imaging: A 12 -week randomized double-blind placebo controlled trial. Arthritis Res Ther 17: 44, 2015.

24. Rezus E, Floria M, Grigoriu A, Tamba BI and Rezus C: Cardiovascular Risk Factors in Chronic Inflammatory Rheumatic Diseases: Modern Assessment and Diagnosis. Curr Vasc Pharmacol 13: 716-724, 2015.

25. Avouac J, Walker U, Tyndall A, Kahan A, Matucci-Cerinic M, Allanore Y, Miniati I, Muller A, Iannone F, Distler O, et al EUSTAR: Characteristics of joint involvement and relationships with systemic inflammation in systemic sclerosis: Results from the EULAR Scleroderma Trial and Research Group (EUSTAR) database. J Rheumatol 37: 1488-1501, 2010.

26. Diab S, Dostrovsky N, Hudson M, Tatibouet S, Fritzler MJ, Baron M and Khalidi N; Canadian Scleroderma Research Group: Systemic sclerosis sine scleroderma: A multicenter study of 1417 subjects. J Rheumatol 41: 2179-2185, 2014.

27. Oldfield V and Lyseng-Williamson KA: Bosentan: A review of its use in pulmonary arterial hypertension and systemic sclerosis. Am J Cardiovasc Drugs 6: 189-208, 2006.

28. Nadashkevich O, Davis P, Fritzler M and Kovalenko W: A randomized unblinded trial of cyclophosphamide versus azathioprine in the treatment of systemic sclerosis. Clin Rheumatol 25: 205-212, 2006

29. Badesch DB, Hill NS, Burgess G, Rubin LJ, Barst RJ, Galiè N and Simonneau G; SUPER Study Group: Sildenafil for pulmonary arterial hypertension associated with connective tissue disease. J Rheumatol 34: 2417-2422, 2007.

30. Galiè N, Brundage BH, Ghofrani HA, Oudiz RJ, Simonneau G, Safdar Z, Shapiro S, White RJ, Chan M, Beardsworth A, et al Pulmonary Arterial Hypertension and Response to Tadalafil (PHIRST) Study Group: Tadalafil therapy for pulmonary arterial hypertension. Circulation 119: 2894-2903, 2009.

31. Barst RJ, McGoon M, McLaughlin V, Tapson V, Rich S, Rubin L, Wasserman K, Oudiz R, Shapiro S, Robbins IM, et al; Beraprost Study Group: Beraprost therapy for pulmonary arterial hypertension. J Am Coll Cardiol 41: 2119-2125, 2003.

32. Galiè N, Humbert M, Vachiéry JL, Vizza CD, Kneussl M, Manes A, Sitbon O, Torbicki A, Delcroix M, Naeije R, et al; Arterial Pulmonary Hypertension and Beraprost European (ALPHABET) Study Group: Effects of beraprost sodium, an oral prostacyclin analogue, in patients with pulmonary arterial hypertension: A randomized, double-blind, placebo-controlled trial. J Am Coll Cardiol 39: 1496-1502, 2002.

33. Vacca A, Meune C, Gordon J, Chung L, Proudman S, Assassi S, Nikpour M, Rodriguez-Reyna TS, Khanna D, Lafyatis R, et al; Scleroderma Clinical Trial Consortium Cardiac Subcommittee: Cardiac arrhythmias and conduction defects in systemic sclerosis. Rheumatology (Oxford) 53: 1172-1177, 2014.

34. Gheorghevici TS, Veliceasa B, Puha B, Toader S, Alexa ID and Alexa O: Preoperative Hemoglobin Dynamics in Patients with Trochanteric Fractures. A multivariate analysis. Rev Chim Buchar 69: 3320-3324, 2018

35. Khanna D, Hays RD and Furst DE: Functional disability and other health-related quality-of-life domains: Points to consider for clinical trials in systemic sclerosis. Rheumatology (Oxford) 56 (Suppl 5): v17-v22, 2017.

36. Baron M, Hudson M, Tatibouet S, Steele R, Lo E, Gravel S, Gyger G, El Sayegh T, Pope J, Fontaine A, et al: The Canadian systemic sclerosis oral health study: Orofacial manifestations and oral health-related quality of life in systemic sclerosis compared with the general population. Rheumatology (Oxford) 53: 1386-1394, 2014

37. Burlui A, Graur M, Gherasim A, Cardoneanu A and Rezus E: The role of adipokines in inflammation and connective tissue diseases: Can we face the challenge? Int J Med Dent 8: 26-33, 2018
38. Siegert E, March C, Otten L, Makowka A, Preis E, Buttgereit F, Riemekasten G, Müller-Werdan U and Norman K: Prevalence of sarcopenia in systemic sclerosis: Assessing body composition and functional disability in patients with systemic sclerosis. Nutrition 55-56: 51-55, 2018.

39. De Cata A, Inglese M, Molinaro F, De Cosmo S, Rubino R, Bernal $\mathrm{M}$ and Mazzoccoli G: Digital ulcers in scleroderma patients: A retrospective observational study. Int J Immunopathol Pharmacol 29: 180-187, 2016.

40. Ughi N, Crotti C and Ingegnoli F: Effectiveness and safety of oxycodone/naloxone in the management of chronic pain in patients with systemic sclerosis with recurrent digital ulcers: Two case reports. Clin Interv Aging 11: 307-311, 2016.

41. Merz EL, Assassi S and Malcarne VL: Pain and Its Management in Systemic Sclerosis. Curr Treatm Opt Rheumatol 4: 255-267, 2018.

42. Alexa T, Marza A, Voloseniuc T and Tamba B: Enhanced analgesic effects of tramadol and common trace element coadministration in mice. J Neurosci Res 93: 1534-1541, 2015.

43. Luca FA, Ioan CA, Sasu C and Luca AC: The Impact of Public Health Care Services on the Patients' Perception as Regards the Health Institutions Brand on the Background of the Health Reform in Romania. Rev Res Soc Intervention 49: 80, 2015.

44. Carausu EM, Paris S, Burlea LS, Tucmeanu AI and Antohe I: The Crisis Impact on the Romanian Health System and Population Health. Rev Res Soc Intervention 57: 120-137, 2017.

45. Peytrignet S, Denton CP, Lunt M, Hesselstrand R, Mouthon L, Silman A, Pan X, Brown E, Czirják L, Distler JHW, et al: Disability, fatigue, pain and their associates in early diffuse cutaneous systemic sclerosis: The European Scleroderma Observational Study. Rheumatology (Oxford) 57: 370-381, 2018.

46. Herrick AL, Pan X, Peytrignet S, Lunt M, Hesselstrand R, Mouthon L, Silman A, Brown E, Czirják L, Distler JHW, et al: Treatment outcome in early diffuse cutaneous systemic sclerosis: The European Scleroderma Observational Study (ESOS). Ann Rheum Dis 76: 1207-1218, 2017.

47. Lambova S: Cardiac manifestations in systemic sclerosis. World J Cardiol 6: 993-1005, 2014.

48. Wallace B, Kafaja S, Furst DE, Berrocal VJ, Merkel PA, Seibold JR, Mayes MD and Khanna D: Reliability, validity and responsiveness to change of the Saint George's Respiratory Questionnaire in early diffuse cutaneous systemic sclerosis. Rheumatology (Oxford) 54: 1369-1379, 2015.

49. Delcroix M and Howard L: Pulmonary arterial hypertension: The burden of disease and impact on quality of life. Eur Respir Rev 24: 621-629, 2015.

50. Almeida C, Almeida I and Vasconcelos C: Quality of life in systemic sclerosis. Autoimmun Rev 14: 1087-1096, 2015.

51. Park EH, Strand V, Oh YJ, Song YW and Lee EB: Health-related quality of life in systemic sclerosis compared with other rheumatic diseases: A cross-sectional study. Arthritis Res Ther 21: 61, 2019.

52. Mugii N, Hasegawa M, Matsushita T, Kondo M, Orito H, Yanaba K, Komura K, Hayakawa I, Hamaguchi Y, Ikuta M, et al: The efficacy of self-administered stretching for finger joint motion in Japanese patients with systemic sclerosis. J Rheumatol 33: 1586-1592, 2006

53. Volkmann ER and Tashkin DP: Treatment of Systemic Sclerosis-related Interstitial Lung Disease: A Review of Existing and Emerging Therapies. Ann Am Thorac Soc 13: 2045-2056, 2016.

54. Young A, Namas R, Dodge C and Khanna D: Hand impairment in systemic sclerosis: Various manifestations and currently available treatment. Curr Treatm Opt Rheumatol 2: 252-269, 2016.

55. Hughes M, Ong VH, Anderson ME, Hall F, Moinzadeh $\mathrm{P}$, Griffiths B, Baildam E, Denton CP and Herrick AL: Consensus best practice pathway of the UK Scleroderma Study Group: Digital vasculopathy in systemic sclerosis. Rheumatology (Oxford) 54: 2015-2024, 2015.

56. Alexa ID, Pancu AG, Morosanu AI, Ghiciuc CM, Lupusoru C, Prada GI and Cepoi V: The impact of self-medication with NSAIDS/analgesics in a North-Eastern region of Romania. Farmacia 62: 1164-1170, 2014.

57. Finch MB, Dawson J and Johnston GD: The peripheral vascular effects of nifedipine in Raynaud's syndrome associated with scleroderma: A double blind crossover study. Clin Rheumatol 5: 493-498, 1986

58. Thompson AE, Shea B, Welch V, Fenlon D and Pope JE: Calcium-channel blockers for Raynaud's phenomenon in systemic sclerosis. Arthritis Rheum 44: 1841-1847, 2001. 
59. Kowal-Bielecka O, Fransen J, Avouac J, Becker M, Kulak A Allanore Y, Distler O, Clements P, Cutolo M, Czirjak L, et al; EUSTAR Coauthors: Update of EULAR recommendations for the treatment of systemic sclerosis. Ann Rheum Dis 76: $1327-1339,2017$

60. Omair MA, Alahmadi A and Johnson SR: Safety and effectiveness of mycophenolate in systemic sclerosis. A systematic review. PLoS One 10: e0124205, 2015.

61. Nihtyanova SI, Brough GM, Black CM and Denton CP: Mycophenolate mofetil in diffuse cutaneous systemic sclerosis--a retrospective analysis. Rheumatology (Oxford) 46: 442-445, 2007.

62. Stratton RJ, Wilson H and Black CM: Pilot study of anti-thymocyte globulin plus mycophenolate mofetil in recent-onset diffuse scleroderma. Rheumatology (Oxford) 40: 84-88, 2001.

63. Vanthuyne M, Blockmans D, Westhovens R, Roufosse F, Cogan E, Coche E, Nzeusseu Toukap A, Depresseux G and Houssiau FA: A pilot study of mycophenolate mofetil combined to intravenous methylprednisolone pulses and oral low-dose glucocorticoids in severe early systemic sclerosis. Clin Exp Rheumatol 25: 287-292, 2007.

64. Takehara K: Treatment of early diffuse cutaneous systemic sclerosis patients in Japan by low-dose corticosteroids for skin involvement. Clin Exp Rheumatol 22 (Suppl 33): S87-S89, 2004.
65. Sharada B, Kumar A, Kakker R, Adya CM, Pande I, Uppal SS, Pande JN, Sunderam KR and Malaviya AN: Intravenous dexamethasone pulse therapy in diffuse systemic sclerosis. A randomized placebo-controlled study. Rheumatol Int 14: 91-94, 1994.

66. Matucci-Cerinic M, Denton CP, Furst DE, Mayes MD, Hsu VM, Carpentier P, Wigley FM, Black CM, Fessler BJ, Merkel PA, et al: Bosentan treatment of digital ulcers related to systemic sclerosis: Results from the RAPIDS-2 randomised, double-blind, placebo-controlled trial. Ann Rheum Dis 70: 32-38, 2011.

67. Nguyen VA, Eisendle K, Gruber I, Hugl B, Reider D and Reider N: Effect of the dual endothelin receptor antagonist bosentan on Raynaud's phenomenon secondary to systemic sclerosis: A double-blind prospective, randomized, placebo-controlled pilot study. Rheumatology (Oxford) 49: 583-587, 2010.

This work is licensed under a Creative Commons Attribution-NonCommercial-NoDerivatives 4.0 International (CC BY-NC-ND 4.0) License. 